\title{
Higher incidence of clear cell adenocarcinoma of the cervix and vagina among women born between 1947 and 1971 in the United States
}

\author{
Emily K. Smith • Mary C. White $\cdot$ Hannah K. Weir • \\ Lucy A. Peipins • Trevor D. Thompson
}

Received: 19 May 2011 / Accepted: 6 October 2011/Published online: 21 October 2011

(C) The Author(s) 2011. This article is published with open access at Springerlink.com

\begin{abstract}
Although the association between in utero exposure to diethylstilbestrol (DES) and clear cell adenocarcinoma of the cervix and vagina (CCA) was first reported among young women, subsequent case reports and cohort studies suggest that an elevated risk for CCA may persist with age. Data from the National Program of Cancer Registries (NPCR) and the Surveillance, Epidemiology and End Results (SEER) Program were used to construct indirect standardized incidence ratios (SIR) comparing CCA risk among women born during the exposure period 1947 through 1971, when DES was prescribed to pregnant women, to the relevant time period for nonexposed women born before or after DES exposure period. CCA incidence among the women born before the DES exposure period (ages 30-54 at diagnosis of CAA) or after the DES exposure period (ages 15-29 at diagnosis) were used to calculate the expected rates for women born during the DES exposure period. Among women aged 15-29 years, CCA risk increased with age and peaked in the 25-29 year age group, but the risk estimates were unstable (SIR $=6.06$; 95\% CI: 0.97, -251.07 , SEER data). Among women aged 40-54 years, CCA risk was
\end{abstract}

The findings and conclusions in this report are those of the authors and do not necessarily represent the official position of the Centers for Disease Control and Prevention.

E. K. Smith · M. C. White $(\varangle) \cdot$ H. K. Weir ·

L. A. Peipins - T. D. Thompson

Epidemiology and Applied Research Branch, Division of Cancer

Prevention and Control, Centers for Disease Prevention and Control, 4770 Buford Highway, NE, Mailstop K55,

Atlanta, GA 30341-3717, USA

e-mail: mxw5@cdc.gov

E. K. Smith

College of Public Health, University of Georgia, Athens,

GA, USA greatest in the 40-44 year age group (SIR $=4.55 ; 95 \% \mathrm{CI}$ : $1.11,40.19$, SEER data and SIR $=3.94 ; 95 \% \mathrm{CI}: 1.06$, 33.01, NPCR/SEER data) and remained significantly elevated throughout this age group in the combined data set. Risk was not elevated among women aged $30-39$ years. The observed risk of CCA, if causally related to DES exposure, reflects a persistent health impact from in utero exposure that is widespread in the general population. When assessing a woman's cancer risks, whether her mother took DES while pregnant may still be a relevant aspect of the medical history for women born during the period of DES use in pregnancy.

Keywords Adenocarcinoma, clear cell .

Diethylstilbesterol · Registries

\section{Introduction}

The association between clear cell adenocarcinoma of the vagina and cervix (CCA) and in utero exposure to diethylstilbestrol (DES) was first described in a case series in 1971 [1]. Since then, the strong and causal association between in utero DES exposure and CCA has been firmly established through the follow-up of several DES exposed cohorts, both in the United States and the Netherlands [2, 3]. Early analyses described an excess of CCA that peaked during late adolescence and early adulthood [2, 3], but individual case reports of CCA and follow-up of established cohorts suggest an elevation in risk persisting as the cohort aged $[4,5]$. The established cohorts of exposed women, however, represent only a small fraction of the women who were exposed to DES. Approximately 2-4 million mothers and their offspring in the United States, and perhaps more, may have been exposed to DES during the period when DES was prescribed for pregnant women $[6,7]$. 
The ability to combine incidence data from populationbased central cancer registries that participate in the Centers for Disease Control and Prevention (CDC)'s National Program of Cancer Registries (NPCR) and/or the National Cancer Institute (NCI)'s Surveillance, Epidemiology, and End Results (SEER) Program provides a unique opportunity to examine the potential population impact of in utero DES exposure. Using data from these programs, we conducted an analysis comparing CCA risk among women born during the time period when prenatal exposure to DES was most common with risk of CCA among women born in a period when DES was not in use.

\section{Materials and methods}

Incidence and population data

Cancer incidence data comes from the two federal cancer surveillance programs: the NCI's SEER Program, and the CDC's NPCR $[8,9]$. Briefly, the SEER Program began in 1973 with 5 state cancer registries and 4 others covering $10 \%$ of the US population (SEER-9). The NPCR began in the mid-1990s with support to cancer registries in the remaining 45 states and the District of Columbia. Together, NPCR and SEER cover $100 \%$ of the US population. Patient demographic and cancer related data are collected and reported to CDC and NCI according to standards established by the North American Association of Central Cancer Registries (NAACCR) [10].

We examined invasive clear cell adenoma carcinomas of the cervix or vagina (CCA) using ICD-O-3 morphology code 8310/3 and site codes C52 and C53, respectively [11]. Cancer incidence data meeting high quality standards [10] for women aged 15-54 years at diagnosis were extracted from both the SEER and the NPCR databases. Information for women diagnosed from 1973 through 2007 was available from the SEER-9 database [12], and for women diagnosed from 1998 through 2006 from the combined SEER/NPCR database (38 cancer registries, covering 63\% of the US population) [9]. County level population estimates were produced by the US Census Bureau with further refinements by NCI [13].

\section{Analyses}

The years between 1947 through 1971 were selected as representative of the period during which pregnant women were most frequently prescribed DES in the United States [6]. Figure 1 illustrates the progression of this cohort of women by age and calendar year and the age groups covered by each registry data source. In 1973, when the SEER Program began, these women were between the ages of 2 and 26 years. In calendar year 2007, the latest year for which SEER data were available, these women were between the ages of 36 and 60 years. In 1998, the first year that combined SEER/NPCR data were available, these women were between the ages of 27 and 51 years. In 2006, the latest year for which combined data were available, these women were between the ages of 35 and 59 years.

Standardized incidence ratio (SIR)s were calculated as follows [14]. SEER-9 data were used to estimate incidence rates among comparison women born prior to 1947 or after 1971 in each 5-year age group (Table 1). The associated incidence rates of CCA in these comparison groups were then multiplied by the age-specific estimates of the population at risk in the target birth cohort in the SEER-9 and combined NPCR/SEER datasets to calculate an expected case count. SEER*Stat [15] was used to estimate the agespecific incidence rates. An observed to expected $(\mathrm{O} / \mathrm{E})$ ratio was calculated for each 5 year age group. The corresponding $95 \%$ confidence intervals were calculated based on exact intervals for the binomial probability of occurrence during the exposure period.

\section{Results}

Among women born between 1947 and 1971, more cases of CCA were observed than expected among women aged 15-29 years (Table 2). Counts increased with age, but risk estimates were unstable with wide confidence intervals. More cases of CCA also were observed among women aged 40-54 years; the SIR estimate was significantly elevated for the 40-44 year age group in both the SEER-9 data set (SIR $=4.55 ; 95 \%$ CI:1.11, 40.19) and NPCR/ SEER data set $(\mathrm{SIR}=3.94 ; 95 \% \mathrm{CI}: 1.06,33.01)$, and significantly elevated throughout the 40-54 year age group in the combined data set. Risk was not elevated among women aged 30-39 years.

\section{Discussion}

This study measured an increase in the incidence of CCA among young women in their late teens and 20s who were born in the United States during the period when DES was prescribed to pregnant women, consistent with the lag period following in utero exposure that had been described in previous reports [1-3]. Although we did not observe elevated risks for women in their 30s, a second peak in risk was observed among women after age 40. Our results are consistent with the experience of the DES exposed cohort in the Netherlands which also demonstrated an elevated risk of CCA after age 40 [5]. In the follow-up of the NCI combined cohort of DES exposed women through 2001, 
Fig. 1 Birth cohorts of women born before, during and after the period of DES use during pregnancy, by age and calendar year

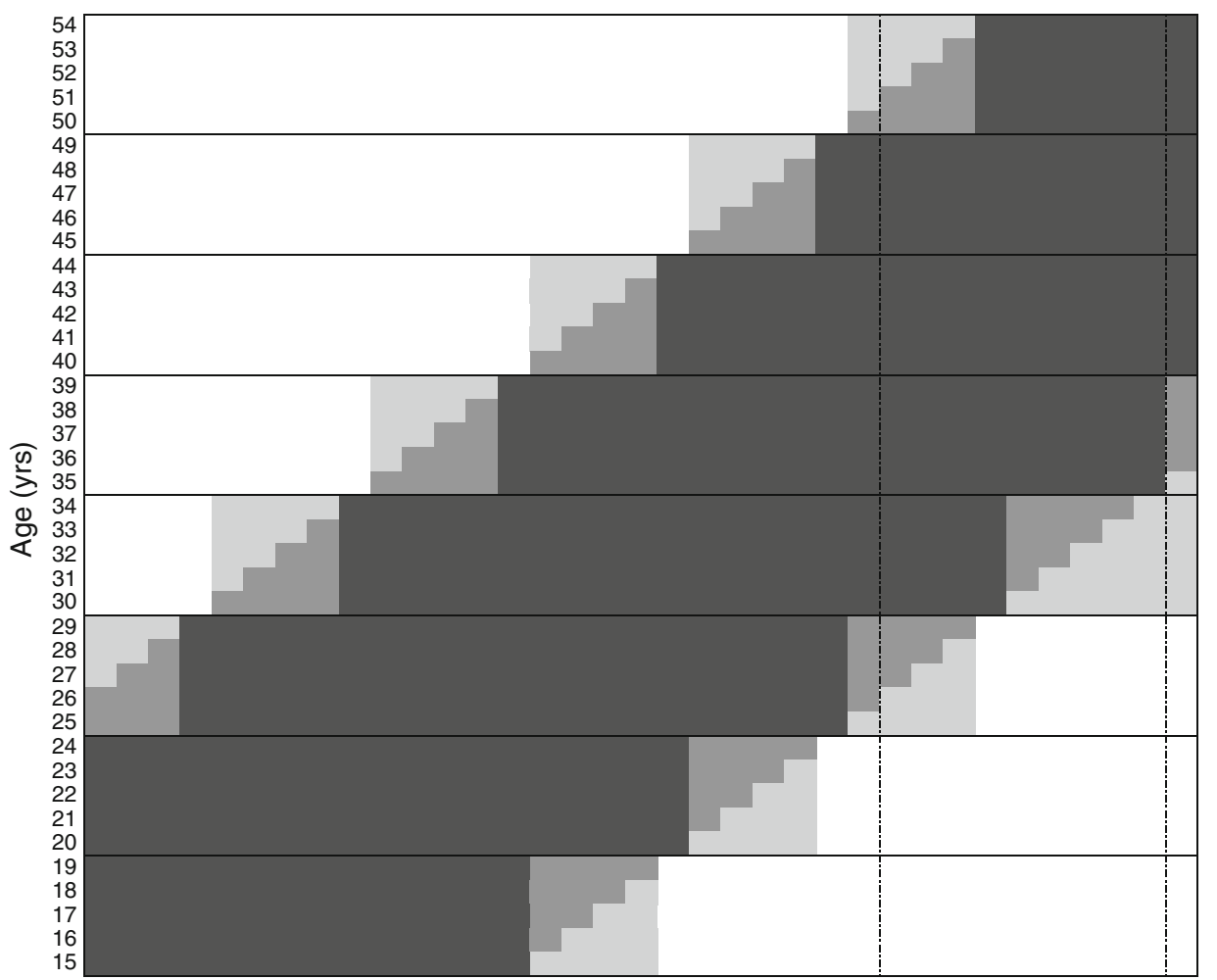

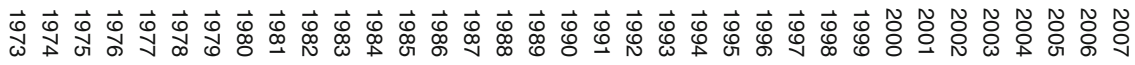
Year of Diagnosis the oldest case occurred at age 39 [4]. A bimodal age distribution in CCA had been observed among women in the Netherlands who had not been exposed in utero to DES, leading the authors to suggest that menarche and menopause might promote the development of CCA [2].

It has been estimated that between 1 and 2 million mothers the United States used DES while pregnant between 1947 and 1971, representing an exposure prevalence of about 1-2\% [6]. If the observed increase in risk for CCA was due primarily to DES exposure, then the magnitude of the risk among DES exposed women was substantially underestimated due to the dilution effect of combining exposed and unexposed women in one group. Studies of cohorts with documented exposure to DES have reported SIRs for CCA of 24 [5] and close to 40 [4]. In addition, we were unable to adjust for temporal variation in prenatal use of DES over time. Although prenatal use of DES occurred primarily between 1947 and 1971, some use occurred starting as early as 1940 and a small number of the women who were born in the early 1940s and assumed to be "unexposed" (Table 1) might have been exposed. The resulting bias could have led to an underestimate of the risk among women in their 30s. The probability that a woman was exposed prenatally to DES was greatest for women born in the early 1950s when the prevalence of use peaked [6]. However, the lack of SEER cancer incidence data before 1972 and the lack of NPCR/SEER data before 1998 limited the range of birth years that could be examined (Table 2). This could have attenuated the measure of risk, especially at the youngest ages. Some analyses used data from SEER registries in nine geographic areas: Atlanta, Connecticut, Detroit, Hawaii, Iowa, New Mexico, San Francisco-Oakland, Seattle-Puget Sound, and Utah. Differences in risk estimates based on SEER data compared to the combined NPCR/SEER data, which includes many more areas, could be influenced by geographic differences in the prevalence of DES use.

Other than older age, DES is the most studied risk factor for CCA. Even among women with known in utero exposure to DES, however, the incidence rate of CCA is very 
Table 1 Diagnosis years and age-specific annual incidence rates of clear cell adenocarcinoma of the cervix and vagina in the standard population of unexposed women (women born before 1947 or after 1971)

\begin{tabular}{llll}
\hline $\begin{array}{l}\text { Age at diagnosis } \\
\text { (years) }\end{array}$ & $\begin{array}{l}\text { Year } \\
\text { of birth }\end{array}$ & $\begin{array}{l}\text { Diagnosis } \\
\text { years }\end{array}$ & $\begin{array}{l}\text { CCA rate per } \\
\text { million among the } \\
\text { unexposed cohort }\end{array}$ \\
\hline $50-54$ & $1919-1946$ & $1973-1996$ & 0.585 \\
$45-49$ & $1924-1946$ & $1973-1991$ & 0.275 \\
$40-44$ & $1929-1946$ & $1973-1986$ & 0.244 \\
$35-39$ & $1934-1946$ & $1973-1981$ & 0.549 \\
$30-34$ & $1939-1946$ & $1973-1976$ & 0.385 \\
$25-29$ & $1972-1982$ & $2001-2007$ & 0.157 \\
$20-24$ & $1972-1987$ & $1996-2007$ & 0.376 \\
$15-19$ & $1972-1992$ & $1991-2007$ & 0.267 \\
\hline
\end{tabular}

Source: Surveillance, Epidemiology, and End Results (SEER) Program (www.seer.cancer.gov) SEER*Stat Database: Incidence-SEER 17 Regs Research Data + Hurricane Katrina Impacted Louisiana Cases, Nov 2009 Sub (1973-2007 varying), Surveillance Research Program, Cancer Statistics Branch, released April 2010, based on the November 2009 submission

low. The availability of high quality cancer incidence data with large nationwide coverage in the NPCR/SEER database enabled the examination of the occurrence of a very rare cancer using indirect standardization of rates. When age-specific risk estimates could be obtained using both SEER data and the combined NPCR/SEER data, the larger numbers available from the combined data set resulted in more stable estimates. The methods employed for this analysis could be repeated at periodic intervals in the future to examine CCA risk as women age. These methods also may have application for the examination of temporal trends or birth cohort patterns for other rare cancers.

These data suggest that the cohort of US women born during the period of DES use by pregnant women experienced an increased risk for CCA that continued for decades, longer than had been projected previously [16]. If the marked elevated risk of CCA among this birth cohort was due primarily to in utero DES exposure, our findings suggest that the large number of women exposed in utero to DES in the United States may still be at special risk for CCA as they grow older. The American Congress of Obstetricians and Gynecologists advises that women exposed to DES in utero may need more frequent cervical cytology screening than that recommended for other women [17]. The National Cancer Institute advises that such exposed women also be given a "four-quadrant" Pap test, in which cell samples are taken from all sides of the upper vagina [18]. The American Cancer Society also specifies some differences in cervical screening recommendations for women with in utero exposure to DES [19]. Women exposed to DES in utero also have been shown to be at elevated risk of breast cancer [20]. To adequately assess a woman's risks for developing cancer and to inform screening decisions for breast and cervical cancer,

Table 2 Observed $(\mathrm{O})$ and expected $(\mathrm{E})$ case counts and observed to expected $(\mathrm{O} / \mathrm{E})$ incidence ratio of clear cell adenocarcinoma of the cervix and vagina and year of diagnosis among women born between 1947 and 1971 by age at diagnosis

\begin{tabular}{|c|c|c|c|c|c|c|}
\hline \multirow{2}{*}{$\begin{array}{l}\text { Age at diagnosis } \\
\text { (years) }\end{array}$} & \multirow[t]{2}{*}{ Year of birth } & \multirow{2}{*}{$\begin{array}{l}\text { Diagnosis } \\
\text { year }\end{array}$} & \multirow{2}{*}{$\begin{array}{l}\text { Woman-years } \\
\text { at risk }\end{array}$} & \multicolumn{2}{|l|}{ Count } & \multirow[t]{2}{*}{$\mathrm{O} / \mathrm{E}(95 \% \mathrm{CI})$} \\
\hline & & & & $\mathrm{E}$ & $\mathrm{O}$ & \\
\hline & & & SEER-9 & & & \\
\hline $50-54$ & $1947-1957$ & 2001-2007 & $6,804,953$ & 3.98 & 7 & $1.76(0.54,5.55)$ \\
\hline $45-49$ & $1947-1962$ & 1996-2007 & $12,340,335$ & 3.40 & 6 & $1.77(0.38,10.91)$ \\
\hline $40-44$ & $1947-1967$ & 1991-2007 & $17,976,258$ & 4.39 & 20 & $4.55(1.11,40.19)$ \\
\hline $35-39$ & $1947-1971$ & 1986-2006 & $22,012,143$ & 12.09 & 17 & $1.41(0.41,7.49)$ \\
\hline $30-34$ & $1947-1971$ & $1981-2001$ & $21,875,328$ & 8.43 & 8 & $0.95(0.13,42.13)$ \\
\hline $25-29$ & $1947-1971$ & 1976-1996 & $20,996,957$ & 3.30 & 20 & $6.06(0.97,51.07)$ \\
\hline $20-24$ & 1949-1971 & 1973-1991 & $17,762,944$ & 6.67 & 20 & $3.00(1.00,12.06)$ \\
\hline \multirow[t]{2}{*}{$15-19$} & $1954-1971$ & $1973-1986$ & $12,793,442$ & 3.42 & 8 & $2.34(0.63,10.62)$ \\
\hline & & & NPCR/SEER data & & & \\
\hline $50-54$ & $1947-1956$ & 2001-2006 & $59,320,387$ & 34.71 & 77 & $2.22(1.07,5.32)$ \\
\hline $45-49$ & 1949-1961 & 1998-2006 & $95,727,032$ & 26.35 & 93 & $3.53(1.17,17.42)$ \\
\hline $40-44$ & 1954-1966 & 1998-2006 & $101,761,290$ & 24.86 & 98 & $3.94(1.06,33.01)$ \\
\hline $35-39$ & 1959-1971 & 1998-2006 & $97,726,456$ & 53.69 & 53 & $0.99(0.32,4.94)$ \\
\hline $30-34$ & 1964-1971 & 1998-2001 & $40,515,385$ & 15.61 & 13 & $0.83(0.13,35.40)$ \\
\hline
\end{tabular}

Source: Data are from population-based cancer registries that participate in the National Program of Cancer Registries (NPCR) and/or the Surveillance, Epidemiology, and End Results (SEER) Program and meet high quality data criteria. These registries cover $79.5 \%$ of the population for 1999-2006 
information on possible prenatal exposure to DES, if available, may be a relevant factor to consider for women born when DES was prescribed to pregnant women.

Acknowledgments This research was supported in part by an appointment (EKS) to the Research Participation Program at the Centers for Disease Control and Prevention administered by the Oak Ridge Institute for Science and Education through an interagency agreement between the US Department of Energy and CDC.

Open Access This article is distributed under the terms of the Creative Commons Attribution Noncommercial License which permits any noncommercial use, distribution, and reproduction in any medium, provided the original author(s) and source are credited.

\section{References}

1. Herbst AL, Ulfelder H, Poskanzer DC (1971) Adenocarcinoma of the vagina. Association of maternal stilbestrol therapy with tumor appearance in young women. N Engl J Med 284(15):878-881

2. Hanselaar A, Loosbroek Mv, Schuurbiers O, Helmerhorst T, Bulten J, Bernheim J (1997) Clear cell adenocarcinoma of the vagina and cervix. Cancer 79(11):2229-2236

3. Hatch EE, Palmer JR, Titus-Ernstoff L, Noller KL, Kaufman RH, Mittendorf $\mathrm{R}$ et al (1998) Cancer risk in women exposed to diethylstilbestrol in utero. JAMA 280(7):630-634

4. Troisi R, Hatch EE, Titus-Ernstoff L, Hyer M, Palmer JR, Robboy SJ et al (2007) Cancer risk in women prenatally exposed to diethylstilbestrol. Int J Cancer 121(2):356-360

5. Verloop J, van Leeuwen FE, Helmerhorst TJ, van Boven HH, Rookus MA (2010) Cancer risk in DES daughters. Cancer Causes Control 21(7):999-1007

6. Swan SH (2000) Intrauterine exposure to diethylstilbestrol: longterm effects in humans. APMIS 108(12):793-804

7. Giusti RM, Iwamoto K, Hatch EE (1995) Diethylstilbestrol revisited: a review of the long-term health effects. Ann Intern Med 122(10):778-788

8. Hankey BF, Ries LA, Edwards BK (1999) The surveillance, epidemiology, and end results program: a national resource. Cancer Epidemiol Biomarkers Prev 8(12):1117-1121
9. US Cancer Statistics Working Group (2010) United States cancer statistics: 1999-2006 incidence and mortality web-based report. US Department of Health and Human Services, Centers for Disease Control and Prevention and National Cancer Institute, Atlanta

10. Havener LA, Thornton M (eds) (2008) Standards for cancer registries, vol II, Data standards and data dictionary, 13th edn. North American Association of Central Cancer Registries, Inc. (NAACCR), Springfield, IL

11. Fritz AP, Jack A (2000) International classification of diseases of oncology. World Health Organization, Geneva

12. National Cancer Institute, DCCPS, Surveillance Research Program, Cancer Statistics Branch (2010) Surveillance, Epidemiology, and End Results (SEER) Program Research Data (1973-2007). Released April 2010

13. National Cancer Institute, DCCPS, Surveillance Research Program, Cancer Statistics Branch (2010) Surveillance, Epidemiology, and End Results Program SEER*State Database: US population data (1969-2007). Released April 2010. Available from: http://seer.cancer.gov/resources

14. Rothman KJ, Greenland S, Lash TL (2008) Modern epidemiology, 3rd edn. Lippincott Williams \& Wilkins, Philadelphia

15. SEER*Stat software (seer.cancer.gov/seerstat) (2007) 6 edn: Surveillance Research Program, National Cancer Institute

16. Melnick S, Cole P, Anderson D, Herbst A (1987) Rates and risks of diethylstilbestrol-related clear-cell adenocarcinoma of the vagina and cervix. An update. N Engl J Med 316(9):514-516

17. ACOG Committee on Practice Bulletins (2009) Cervical cytology screening. Obstet Gynecol 114(6):1409-1420

18. National Cancer Institute (2006) DES: questions and answers. US Department of Health and Human Services [updated 11/29/06]. Available from: http://www.cancer.gov/cancertopics/factsheet/ Risk/DES

19. Smith RA, Cokkinides V, Brooks D, Saslow D, Brawley OW (2010) Cancer screening in the United States, 2010: a review of current American cancer society guidelines and issues in cancer screening. CA Cancer J Clin 60:99-119

20. Palmer JR, Wise LA, Hatch EE, Troisi R, Titus-Ernstoff L, Strohsnitter W et al (2006) Prenatal diethylstilbestrol exposure and risk of breast cancer. Cancer Epidemiol Biomarkers Prev 15(8):1509-1514 